\title{
Comportamento reprodutivo de vacas de corte manejadas em pastagem natural com duas cargas animais e duas idades à desmama
}

\author{
Caius Barcellos de Pellegrini ${ }^{1}$, Luiz Felipe Dias Lopes $^{2}$
}

\author{
1 Programa de Pós-Graduação em Zootecnia - Faculdade de Agronomia - UFRGS. \\ 2 Programa de Pós-Graduação em Engenharia de Produção - UFSM.
}

RESUMO - Este trabalho foi realizado para avaliar o desempenho produtivo e reprodutivo de 52 vacas de corte mestiças Charolês $\times$ Nelore em pastagem natural. O experimento foi iniciado em 4/8/2003, quando as vacas em gestação foram distribuídas uniformemente por peso e condição corporal em duas cargas animais (280 e $360 \mathrm{~kg}$ PV/ha). O desmame precoce foi realizado em 26 vacas quando os bezerros(as) atingiram em média 100 dias de idade e o desmame convencional, em 26 vacas quando os bezerros(as) atingiram em média 180 dias de idade. As vacas submetidas ao desmame precoce tiveram maior ganho médio diário em comparação àquelas submetidas ao desmame convencional (0,471 vs. 0,255 kg/dia, respectivamente). Houve interação significativa entre as idades de desmame e os períodos para a condição corporal das vacas. As vacas submetidas ao desmame precoce apresentaram melhor condição corporal na época do desmame convencional $(3,5$ vs. 2,8) e ao final do acasalamento (3,0 vs. 2,8). A carga animal não afetou significativamente o ganho médio diário nem a condição corporal das vacas. A taxa de prenhez das vacas do desmame precoce $(60,0 \%)$ foi significativamente superior à do desmame convencional (12,0\%), no entanto, as cargas animais não diferiram entre si (7,7\% vs. 15,4\%, respectivamente). Nos bezerros submetidos ao desmame precoce, o ganho médio diário e o peso vivo aos 180 dias foram significativamente inferiores aos observados nos bezerros do desmame convencional. O manejo da pastagem com as duas cargas animais no pós-parto das vacas e as duas idades de desmame dos bezerros não influenciam o peso médio e o ganho médio diário dos bezerros até os 14 meses de idade.

Palavras-chave: condição corporal, ganho médio diário, idades ao desmame, peso corporal, taxa de prenhez

\section{Reproductive performance of beef cows maintained at two stocking rates and two ages of weaning on natural pasture}

\begin{abstract}
The study was conducted to evaluate productive and reproductive performance of 52 crossbred Charolais $\times$ Nellore beef cows on natural pasture. The experiment started on August 04, 2003, when pregnant cows were uniformly distributed by weight and body condition at two stocking rates (CA280 $=280 \mathrm{~kg} \mathrm{LW} / \mathrm{ha}$ and CA360 $=360 \mathrm{~kg} \mathrm{LW} / \mathrm{ha}$ ). Early weaning was imposed to 26 cows when calves reached average of 100 days of age and conventional weaning, when calves were approximately 180 days old. Cows submitted to early weaning had average daily gain higher than cows submitted to conventional weaning ( 0.539 vs. $0.257 \mathrm{~kg} /$ day, respectively). There was significant interaction between weaning ages and periods for body condition of cows. Cows submitted to early weaning presented higher body condition at conventional weaning (3.5 vs. 2.8) and at the end of mating period (3.0 vs. 2.8) than the conventional weaning. The stocking rate did not significantly affect the average daily gain and body condition of cows (CA280 $=0.101 \mathrm{~kg} /$ day, 2.7 and CA360 $=0.214 \mathrm{~kg} /$ day, 2.7, respectively). The pregnancy rate of cows under early weaning $(60.0 \%)$ was significantly better than for those under conventional weaning (12.0\%); however, the stocking rates did not differ (CA280 $=7.7 \%$ vs. CA360 $=15.4 \%$ ). In calves submitted to early weaning, average daily gain and live weight at 180 days were significantly lower than those of calves at conventional weaning. The post-partum management of cows and two ages of weaning calves evaluated did not affect the development of calves until 14 months of age.
\end{abstract}

Key Words: average daily gain, body condition, body weight, pregnancy rate, weaning ages

\section{Introdução}

As pastagens naturais do Rio Grande do Sul cobrem uma área pastoril útil de 46,6\% (Hasenack et al., 2007) e são a base forrageira para a produção bovina. Os rebanhos de cria normalmente são mantidos em áreas de solos de menor fertilidade e, na maioria das vezes, com alta carga animal, incompatível com capacidade de suporte da pastagem natural (Quadros \& Lobato, 1996; Simeone \& Lobato, 1996). Ajustar a carga animal à disponibilidade da pastagem significa controlar a quantidade de pasto que cada animal deve encontrar diariamente à sua disposição (Nabinger, 2006). 
A adequação de carga animal em pastagem natural com vacas primíparas é uma alternativa de manejo para melhorar a eficiência reprodutiva, contudo, os estudos têm apresentado resultados distintos (Quadros \& Lobato, 1996; Gottschall \& Lobato, 1996), evidenciando que outros fatores, como peso vivo e condição corporal ao parto e ao início do acasalamento, ano e solo, também são determinantes do comportamento reprodutivo (Lobato, 2003). Altas cargas animais durante o pré e/ou pós-parto dificultam a recuperação da condição corporal da vaca após o parto, comprometendo seu desempenho reprodutivo e a produtividade do ciclo seguinte (Osoro, 1989; Lobato, 1999). Quadros \& Lobato (1996) constataram em vacas primíparas ganhos médios diários similares (0,581 e 0,502 kg/dia) para cargas animais ( 280 e $320 \mathrm{~kg} \mathrm{PV/ha).} \mathrm{Esses} \mathrm{resultados} \mathrm{foram} \mathrm{relacionados}$ à adequada quantidade e qualidade de forragem disponível aos animais.

Além da redução da carga animal (Simeone \& Lobato, 1996), uma alternativa para aumentar a taxa de reprodução do rebanho de cria é o desmame antecipado dos bezerros (Lobato \& Barcellos, 1992; Restle \& Vaz, 1998), utilizado preferencialmente em vacas com baixa condição corporal. $\mathrm{O}$ desmame precoce dos bezerros entre 60 e 90 dias de idade resulta em aumento da taxa de reprodução, pois, com a interrupção da produção de leite, as exigências nutricionais da vaca diminuem e os nutrientes ingeridos são direcionados para outras funções, especialmente a reprodutiva (Moore \& Rocha, 1983; Restle et al., 2001). Essa técnica beneficia principalmente a vaca que pare na primeira metade da época de parição (Restle \& Vaz, 1998).

Este trabalho foi realizado com o objetivo de avaliar o desempenho reprodutivo de vacas em pastagem natural manejada com duas cargas animais submetidas ao desmame precoce ou convencional dos bezerros. Avaliou-se ainda o desenvolvimento dos bezerros até os 14 meses de idade.

\section{Material e Métodos}

O experimento foi conduzido na fazenda Barcellos, município de Dilermando de Aguiar, Rio Grande do Sul. O período de avaliação foi de 4/8/2003 a 4/4/2004.

A vegetação natural da área experimental é constituída principalmente de espécies da família Gramineae (Poaceae), como Andropogon lateralis Nees, Sporobolus indicus (L.) R.Br., Paspalum notatum Flügge. Parodi, Paspalum nicorae Parodi e Paspalum plicatulum Michx. Entre as espécies da família Leguminosae (Fabaceae), destaca-se o Desmodium incanum DC. As espécies de Compositae (Asteraceae) de maior destaque são Baccharis coridifolia DC e Baccharis trimera (Less.).
O experimento foi iniciado em 4/8/2003 com 52 vacas prenhes mestiças Charolês $\times$ Nelore estratificadas aleatoriamente por peso corporal e condição corporal, distribuídas ao acaso nas duas cargas animais: 26 vacas em um potreiro com carga animal de $280 \mathrm{~kg}$ (PC)/ha; e 26 em um potreiro com carga animal de $360 \mathrm{~kg}$ (PC)/ha.

Em 7/1/2004, foi realizado o desmame de $50 \%$ dos bezerros(as) de cada carga animal, os quais passaram a fazer parte do experimento: 26 bezerros(as) foram desmamados em idade precoce, em média aos 100 dias de idade (7/1/2004); e 26 em desmame convencional, aos 180 dias de idade $(4 / 4 / 2004)$.

Os bezerros foram pesados e identificados com brincos de plástico ao nascimento. As pesagens foram realizadas a cada 28 dias, com jejum prévio. Na ocasião das pesagens, foram tomadas medidas de peso corporal e realizada avaliação subjetiva da condição corporal, segundo metodologia adaptada por Lowman et al. (1973), atribuindo-se valores de 1 a 5 , em que 1 = muito magro e 5 = muito gordo.

Os bezerros do desmame precoce permaneceram em curral por nove dias pós-desmame, com água e oferta de concentrado, a 1\% do peso corporal, com 18\% de proteína bruta. No décimo dia, foram para potreiro de papuã (Urochloa plantaginea), onde receberam o mesmo concentrado até 4/4/2004, ou seja, até aproximadamente os 180 dias de idade, período em que ocorreu o desmame convencional. A partir desta data, foram manejados em pastagem natural e de 1/6/2004 a 1/10/2004 submetidos ao pastejo horário (3 horas/dia) em pastagem cultivada de aveia (Avena strigosa Schreb.) e azevém (Lolium multiflorum Lam.). No período de 2/10/2004 a 29/12/2004, foram mantidos em pastagem natural.

A massa de forragem e a taxa de acúmulo diário de forragem da pastagem natural foram medidas em cada período de avaliação. A massa de forragem foi determinada pela técnica de dupla amostragem, proposta por Haydock \& Shaw (1975). Para determinação da taxa de acúmulo diário, foram alocadas cinco gaiolas de exclusão ao pastejo por potreiro, utilizando-se metodologia descrita por Klingmann et al. (1943). A oferta de forragem foi calculada dividindo-se a massa de forragem pelo número de dias do período somado à taxa de acúmulo diário. O valor obtido foi multiplicado por 100 e dividido pela carga animal.

Os dados qualitativos da pastagem natural não foram analisados, devido à perda do material. O ganho de peso médio diário foi obtido pela diferença entre os pesos finais e iniciais dos animais, dividido pelo número de dias do período.

O delineamento experimental foi o inteiramente casualizado, em arranjo fatorial $2 \times 2$, com parcelas 
subdivididas no tempo, considerando os animais repetições. O modelo matemático utilizado na análise dos parâmetros foi:

$\mathrm{Yijkl}=\mu+\mathrm{CAi}+\mathrm{IDj}+(\mathrm{CA} * \mathrm{ID}) \mathrm{ij}+\mathrm{Ak}(\mathrm{CA} * \mathrm{ID}) \mathrm{ij}+\mathrm{Pl}+$ $(\mathrm{CA} * \mathrm{P}) \mathrm{il}+(\mathrm{ID} * \mathrm{P}) \mathrm{jl}+(\mathrm{CA} * \mathrm{ID} * \mathrm{P}) \mathrm{ijl}+\sum \mathrm{ijkl}$, em que: $\mathrm{Yijkl}=$ variáveis dependentes; $\mu$ = média de todas as observações; $\mathrm{CAi}$ = efeito do i-ésimo carga animal; IDj = efeito do j-ésimo nível de idade de desmame; CAi*IDj = efeito da interação i-ésimo carga animal $\times$ j-ésimo nível de idade de desmame; Ak (CA*ID)ij = efeito do k-ésimo animal dentro da interação i-ésimo carga animal $\times$ j-ésimo nível de idade de desmame; (erro A); $\mathrm{Pl}=$ efeito do l-ésimo período; $\mathrm{CA} * \mathrm{Pil}=$ efeito da interação i-ésimo carga animal $\times$ l-ésimo período; $\mathrm{ID} * \mathrm{Pjl}=$ efeito da interaçãoj-ésimo nível de idade de desmame × l-ésimo período; $\mathrm{CA}^{*} \mathrm{ID} * \mathrm{Pijl}=$ efeito da interação i-ésimo carga animal $\times$ j-ésimo nível de idade de desmame $\times$ l-ésimo período; $\Sigma \mathrm{ijkl}=$ erro residual (erro B).

Quando detectada diferença entre os tratamentos, realizou-se o teste t de Student (PDIFF) para comparação de médias, adotando-se 5\% como nível máximo de significância das análises. As análises foram feitas com auxílio do procedimento MIXED do aplicativo estatístico SAS (2001).

O índice de prenhez das vacas foi analisado pelo teste qui-quadrado a $5 \%$.

\section{Resultados e Discussão}

Houve pequena variação da massa de forragem e taxa de acúmulo diário de forragem entre as duas cargas animais estudadas. Os resultados de oferta de forragem obtidos com a carga animal de $280 \mathrm{~kg}$ PV/ha tenderam a ser superiores ( $\mathrm{P}>0,05)$ aos observados com a carga animal de $360 \mathrm{~kg} \mathrm{PV} / \mathrm{ha}$, mas ambas as ofertas diminuíram com o avanço dos períodos avaliados, em virtude da diminuição da taxa de acúmulo diário de forragem e da massa de forragem (Tabela 1).

$\mathrm{O}$ ganho médio diário das vacas não diferiu $(\mathrm{P}>0,05)$ entre cargas animais e os períodos e foram insatisfatórios nos períodos do pós-parto ao desmame convencional, do desmame precoce ao convencional e durante o acasalamento (Tabela 2).

Os resultados de ganho de peso das vacas foram modestos e variaram de 0,071 a 0,236 kg/dia. Por outro lado, a carga animal não influenciou o ganho de peso das vacas, que foi de $0,101 \mathrm{~kg} /$ dia naquelas mantidas na pastagem com carga animal de $280 \mathrm{~kg} \mathrm{PV} / \mathrm{ha}$, similar $(\mathrm{P}>0,05)$ ao daquelas mantidas com carga de $360 \mathrm{~kg}$ PV/ha (0,214 kg/dia). Esses resultados indicam que a oferta de forragem, aliada ao estado fisiológico das vacas com maior exigência nutricional

Tabela 1 - Características produtivas da pastagem natural utilizada por vacas pluríparas com duas cargas animais

\begin{tabular}{|c|c|c|c|c|c|c|}
\hline \multirow[t]{4}{*}{ Item } & \multicolumn{6}{|c|}{ Período } \\
\hline & \multicolumn{2}{|c|}{ Pós-parto } & \multicolumn{2}{|c|}{ Acasalamento } & \multicolumn{2}{|c|}{ Pós-acasalamento } \\
\hline & \multicolumn{6}{|c|}{ Carga animal } \\
\hline & 280 & 360 & 280 & 360 & 280 & 360 \\
\hline Massa de forragem (kg/ha MS) & 1600 & 1500 & 1400 & 1300 & 1400 & 1200 \\
\hline Taxa de acúmulo diário (kg/ha MS) & 10 & 9 & 12 & 9 & 10 & 8 \\
\hline Oferta de forragem (kg MS/100 kg PV) & 23 & 17 & 20 & 14 & 14 & 9 \\
\hline
\end{tabular}

Pós-parto: 22/8/2003 a 21/11/2003; acasalamento: 22/11/2003 a 22/2/2004; pós-acasalamento: 23/2/2004 a 4/4/2004.

Tabela 2 - Desempenho produtivo de vacas pluríparas avaliadas em pastagem natural com duas cargas animais e duas idades de desmame dos bezerros

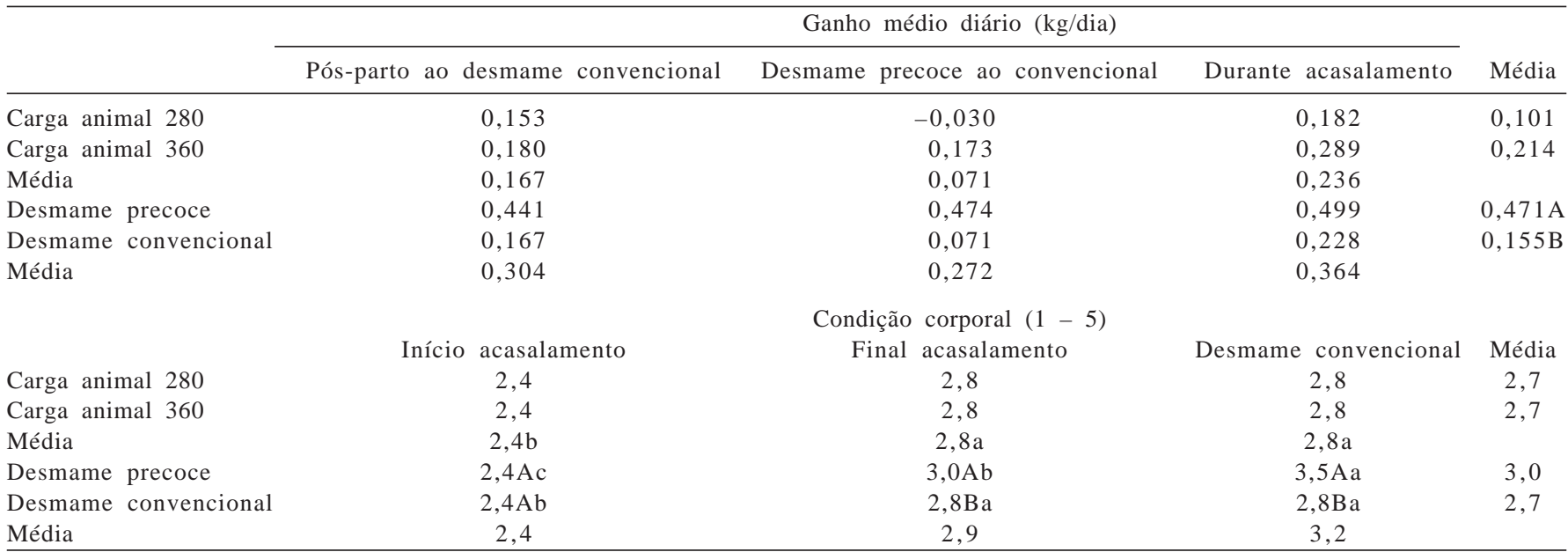

Letras maiúsculas diferentes na coluna e letras minúsculas diferentes na linha diferem $(\mathrm{P}<0,05)$ entre si. 
durante a lactação, foi a causa dos modestos ganhos de peso. A pastagem natural da Depressão Central do Rio Grande do Sul caracteriza-se por áreas de solos com baixa fertilidade e composição florística de espécies naturais da família Gramineae, que diminui a qualidade da forragem com o aumento da quantidade em oferta (Moojen \& Maraschin, 2002). Neste trabalho, provavelmente o principal limitante do desempenho produtivo das vacas em lactação nas cargas animais foi o baixo valor nutricional do pasto, aliado à baixa oferta de forragem, que não atenderam à maior exigência nutricional dos animais.

Os ganhos de peso nas cargas animais obtidos nesta pesquisa estão de acordo com os verificados por Lobato et al. (1998b) com vacas de cria, que ganharam 0,178 kg/dia no pós-parto em pastagem natural. Rovira (1974) associou as perdas de peso e, ou, ganhos muito discretos em vacas lactantes à maior demanda nutricional neste período. Por outro lado, as diferenças nos resultados entre trabalhos sobre adequação de cargas de peso vivo em pastagem natural com vacas primíparas (Quadros \& Lobato, 1996; Gottschall \& Lobato, 1996) e os obtidos nesta pesquisa reforçam o efeito de outros fatores importantes, como peso corporal e condição corporal ao parto, ao início do acasalamento, ano e déficits hídricos de 30 a 60 dias, sobre o comportamento reprodutivo.

A idade de desmame dos bezerros influenciou $(\mathrm{P}<0,05)$ o ganho médio diário das vacas (Tabela 2), que foi maior naquelas submetidas ao manejo com desmame precoce dos bezerros em comparação àquelas do desmame convencional, 0,471 e 0,155 kg/dia, respectivamente. A técnica do desmame precoce dos bezerros favorece as vacas, pois a interrupção da lactação diminui suas exigências (Monje et al., 1993). O maior ganho médio diário e condição corporal obtido nas vacas do desmame precoce em relação às vacas do desmame convencional confirmam a eficiência produtiva da técnica aplicável preferencialmente em vacas de cria com baixa condição corporal.

Houve interação significativa $(\mathrm{P}<0,05)$ entre a idade de desmame dos bezerros e o período para a condição corporal (Tabela 2). A interrupção da amamentação das vacas pelo desmame precoce possibilitou condição corporal final do acasalamento $(3,0)$ e condição corporal desmame convencional $(3,5)$ superiores às das vacas mantidas com seus bezerros ( 2,8 e 2,8 , respectivamente). O maior aumento de condição corporal nas vacas manejadas com desmame precoce dos bezerros ocorreu no final do acasalamento até a época do desmame convencional dos bezerros, reflexo do maior ganho médio diário neste período. Maiores índices de condição corporal de vacas submetidas ao desmame precoce têm sido relatados em outros trabalhos (Moraes
\& Lobato, 1993; Pötter \& Lobato, 2004), e isso indica mudança na partição dos nutrientes quando cessa a amamentação, diminuindo as exigências nutricionais das vacas e permitindo às mesmas recuperar a condição corporal. Vários resultados da literatura indicam que a condição corporal e o ganho médio diário durante o acasalamento são fatores determinantes na decisão entre permitir que os bezerros fiquem junto às mães ou realizar o desmame até a metade do período reprodutivo (Barcellos et al., 1996; Simeone \& Lobato, 1996; Lobato et al., 2000).

Houve diferença significativa $(\mathrm{P}<0,05)$ na taxa de prenhez entre as vacas do desmame precoce $(60 \%)$ e do desmame convencional (12\%) (Tabela 3). O maior desempenho reprodutivo das vacas cuja lactação foi interrompida quando os bezerros atingiram 3 meses de idade dos bezerros em comparação àquelas que permaneceram com seus bezerros até os 6 meses de idade deve-se aos maiores valores de ganho médio diário e condição corporal no final do acasalamento $(\mathrm{P}<0,05)(0,471 ; 3,0$ vs 0,$155 ; 2,8)$, respectivamente.

Esses resultados coincidem com os relatados por outros autores (Simeone \& Lobato, 1996; Restle et al., 2001), que observaram diferenças significativas nas taxas de prenhez de vacas submetidas ao desmame precoce em relação àquelas do desmame convencional, reflexo de maior ganho de peso. Por outro lado, o efeito das cargas animais $280 \mathrm{e}$ $360 \mathrm{~kg}(\mathrm{PV}) /$ ha não influenciou significativamente $(\mathrm{P}>0,05)$ a taxa de prenhez das vacas. As baixas taxas de prenhez em ambas as cargas animais estão associados aos baixos ganhos médios diários, que promoveram pouco acúmulo de condição corporal $(2,8 ; 2,8)$ no final do acasalamento.

A condição corporal ao parto é provavelmente o fator mais importante a afetar o desempenho reprodutivo de vacas de corte (Morrison et al., 1999). Gottschall \& Lobato (1996), em pesquisa com vacas primíparas com baixo peso e condição corporal ao parto submetidas a três cargas animais (280, 320 e 360 kg PV/ha), obtiveram índices reprodutivos extremamente baixos $(8,5 ; 10,4$ e $0 \%$, respectivamente). Somando-se a isso, Richards et al. (1989) observaram vacas perdendo condição corporal durante o período de acasalamento com condição corporal abaixo de 2,5 (escala 1 a 5), resultando

Tabela 3 - Desempenho reprodutivo de vacas pluríparas em pastagem manejada com duas cargas animais e duas idades de desmame dos bezerros

Número animais Taxa de prenhez (\%)

\begin{tabular}{llc}
\hline Carga animal 280 & 13 & 7,7 \\
Carga animal 360 & 13 & 15,4 \\
Desmame precoce & 26 & $60,0 \mathrm{a}$ \\
Desmame convencional & 26 & $12,0 \mathrm{~b}$ \\
\hline
\end{tabular}

Letras minúsculas distintas na coluna diferem $(\mathrm{P}<0,05)$ entre si. 
em bloqueio da atividade cíclica reprodutiva, que só reiniciou quando as vacas atingiram condição corporal 2,8, ao contrário daquelas que mantiveram ou melhoraram sua condição corporal.

Vários autores que estudaram reprodução de vacas com cria observaram que o consumo reduzido de energia, no pré e pós-parto, retarda o crescimento dos folículos ovarianos após o parto, reduz o tamanho dos folículos dominantes, diminui o número de folículos secretores de estrógeno e aumenta a persistência dos folículos menores subordinados, prolongando o intervalo do parto à primeira ovulação (Wiltbank et al., 1962; Perry et al., 1991; Spitzer et al., 1995).

Devido à grande demanda por nutrientes para a lactação, os efeitos inibitórios do ato da mamada pelo bezerro sobre a secreção de GnRH e de gonadotrofinas são mais expressivos em vacas com baixa condição corporal (Rice, 1991). Para obter bons níveis de concepção, o manejo de vacas em reprodução deve incluir estratégias para que a condição corporal ao parto mantenha-se entre 3,5 e 4,0 (escala 1 a 5) e a massa de forragem seja suficiente para evitar perdas de condição corporal durante a lactação (Lobato, 2003). Portanto, a interrupção da lactação com desmame precoce do bezerro permite melhor recuperação do peso vivo e da condição corporal da vaca até o final do acasalamento, possibilitando, com isso, melhor desempenho reprodutivo.

Os resultados obtidos neste experimento permitem concluir que vacas com baixa condição corporal durante o pré e/ou pós-parto devem ser submetidas ao desmame precoce para permitir recuperação de peso e maiores taxas de prenhez. Os baixos desempenhos reprodutivos das vacas nas duas cargas animais avaliadas comprovam que as ofertas de forragem e a qualidade do pasto foram insuficientes, pois refletiram em pequenos ganhos médios diários e condição corporal inferior a 3,0, reduzindo a fertilidade das vacas com cria.

O peso vivo dos bezerros ao nascimento não foi influenciado $(\mathrm{P}>0,05)$ pelas cargas animais nem pelas idades de desmame e apresentou média de 33,0 kg. Houve interação significativa $(\mathrm{P}<0,05)$ entre as idades de desmame dos bezerros e o período para a variável ganho médio diário (Tabela 4).

Os bezerros desmamados em idade convencional tiveram maior $(\mathrm{P}<0,05)$ ganho médio diário e peso vivo aos 180 dias de idade em comparação àqueles do desmame precoce. $\mathrm{O}$ menor ganho de peso nos animais do desmame precoce possivelmente foi ocasionado pela interrupção do consumo de leite e pelo manejo nutricional pós-desmame. Rovira (1996) observou efeito do consumo de leite na variação de $50 \%$ no peso vivo de bezerros. Embora os bezerros submetidos ao desmame aos 3 meses de idade tenham sido mantidos em pastagem de papuã e recebido suplementação com concentrado, o menor ganho médio diário pode estar relacionado à diminuição da qualidade do pasto, que, no final de ciclo, apresenta menor relação folha/caule e altos níveis de constituintes da parede celular.

Comparando o desempenho produtivo de bezerros com distintas idades de desmame, Restle et al. (1999b) observaram que o ganho de peso dos bezerros desmamados aos 3 meses de idade $(0,300 \mathrm{~kg} / \mathrm{dia})$ foi inferior $(\mathrm{P}<0,05)$ ao daqueles desmamados aos 7 meses de idade, $0,464 \mathrm{~kg} /$ dia. Pötter et al. (2004) também observaram diferença significativa $(\mathrm{P}<0,01)$ no ganho médio diário entre bezerros desmamados aos 100 e 180 dias de idade (0,778 e 0,909 kg/dia, respectivamente). O desmame precoce do bezerro pode dificultar a ingestão de nutrientes pela limitação física do rúmen e, consequentemente, possibilitar menor ganho de peso daqueles mantidos em lactação (Restle et al., 1999b). O desmame precoce aumenta a fertilidade da vaca, mas deve ser feito com cuidado para não prejudicar o desenvolvimento do bezerro (Restle et al., 2001), que depende do manejo alimentar adequado após o desmame (Pötter et al., 2004).

O ganho médio diário e o peso vivo aos 180 dias de idade dos bezerros da pastagem manejada com carga animal de $280 \mathrm{~kg}$ PV/ha (0,779 kg/dia; $179 \mathrm{~kg})$ foram semelhantes aos daqueles mantidos na pastagem com carga animal de $360 \mathrm{~kg}$ PV/ha (0,756 kg/dia; $175 \mathrm{~kg})$. Fagundes et al. (2004) também não observaram diferença significativa $(\mathrm{P}>0,05)$ no ganho médio diário $(0,770$ e $0,756 \mathrm{~kg} / \mathrm{dia})$ e no peso à

Tabela 4 - Desempenho produtivo dos bezerros avaliados nas respectivas cargas animais e idades à desmama

\begin{tabular}{|c|c|c|c|c|c|c|}
\hline & \multicolumn{4}{|c|}{ Peso vivo (kg) } & \multicolumn{2}{|c|}{ Ganho médio diário (kg/dia) } \\
\hline & Nascimento & 100 dias & 180 dias & 14 meses & 180 dias & 14 meses \\
\hline Carga animal 280 & 32,6 & 123 & 179 & 217 & 0,779 & 0,163 \\
\hline Carga animal 360 & 33,2 & 120 & 175 & 226 & 0,756 & 0,172 \\
\hline Média & $33,0 \mathrm{D}$ & $122 \mathrm{C}$ & $177 \mathrm{~B}$ & $222 \mathrm{~A}$ & 0,768 & 0,167 \\
\hline Desmame Precoce & 32,8 & 119 & $160 \mathrm{~b}$ & 218 & $0,670 \mathrm{Ab}$ & $0,215 \mathrm{Ba}$ \\
\hline Desmame convencional & 33,2 & 122 & $174 \mathrm{a}$ & 222 & $0,768 \mathrm{Aa}$ & $0,168 \mathrm{Ba}$ \\
\hline Média & $33,0 \mathrm{D}$ & $120 \mathrm{C}$ & $168 \mathrm{~B}$ & $220 \mathrm{~A}$ & $0,719 \mathrm{~A}$ & $0,191 \mathrm{~B}$ \\
\hline
\end{tabular}

Letras maiúsculas na linha diferem $(\mathrm{P}<0,05)$ entre si.

Letras minúsculas na coluna diferem $(\mathrm{P}<0,05)$ entre si. 
desmama (204,5 e 200,12 kg) entre bezerros manejados em pastagens com essas mesmas cargas animais. Osoro (1989) relatou que vacas de alto potencial leiteiro, quando manejadas sob restrição alimentar, tanto em qualidade como em quantidade, repassam para suas crias, pelo leite, os nutrientes destinados às reservas corporais e à reprodução. Com isso, mesmo quando as vacas são manejadas em cargas animais distintas, os bezerros podem apresentar ganhos de peso e peso vivo semelhantes. Os resultados similares de desempenho produtivo das vacas de cria (ganho médio diário e condição corporal) e seus bezerros (ganho médio diário e peso vivo aos 180 dias) nas cargas animais confirmam que vacas com baixa condição corporal no pós-parto direcionam suas reservas corporais para lactação, permitindo desenvolvimento equânime dos bezerros.

A carga animal e idade de desmame não influenciaram $(\mathrm{P}>0,05)$ no peso vivo e ganho de peso aos 14 meses (Tabela 4).

Os valores médios de ganho médio diário e peso vivo aos 14 meses dos animais foram 0,179 kg/dia e 221,0 kg, respectivamente, para os tratamentos cargas animais e idades de desmame. Embora os bezerros manejados no desmame precoce tenham apresentado ganho médio diário e peso vivo aos 180 dias significativamente inferiores aos bezerros do desmame convencional, essa diferença não foi observada no ganho médio diário e peso vivo até 14 meses de idade $(\mathrm{P}>0,05)$. Esses resultados são semelhantes aos encontrados por Restle et al. (1999b) e Pötter et al. (2004), que não verificaram diferença de desempenho produtivo entre bezerros de até um ano de idade e aos dois anos, desmamados em diferentes idades. De acordo com Restle \& Vaz (1998), o objetivo do desmame precoce não é promover ganhos de peso superiores aos obtidos ao pé da vaca, e sim promover um desenvolvimento que não prejudique o desempenho futuro do animal. A determinação do plano nutricional aplicado aos animais durante a recria depende do sistema de produção almejado.

\section{Conclusões}

A menor carga animal (280 kg PV/ha) não permite maior acúmulo de forragem em pastagem natural. Vacas mantidas em menor carga animal e com baixa condição corporal ao início do acasalamento não recuperam o peso nem a condição corporal durante o acasalamento e não obtêm bom desempenho reprodutivo. O desmame definitivo dos bezerros em idade precoce permite às vacas maior recuperação de peso e condição corporal e melhora a taxa de prenhez. Bezerros desmamados aos 100 dias de idade têm desenvolvimento aos 14 meses semelhante àqueles desmamados aos 180 dias de idade.

\section{Agradecimentos}

Ao Dr. José Henrique Souza da Silva, pela colaboração nas análises estatísticas.

Aos colegas Alcides Pilau e Davi Teixeira dos Santos, pelo auxílio na organização deste trabalho.

\section{Referências}

BARCELlOS, J.O.J.; SILVA, M.D.; SILVA, J.L.C. Efeitos do desmame precoce na taxa de prenhez de vacas Santa Gertrudis. Arquivos da Faculdade de Veterinária da UFRGS, v.24, n.2, p.30-44, 1996.

FAGUNDES, J.I.B.; LOBATO, J.F.P.; SCHENKEL, F.S. Efeito da carga animal na produção de leite de vacas de corte primíparas e no desenvolvimento de seus bezerros. Revista Brasileira de Zootecnia, v.33, n.2, p.412-419, 2004.

GOTTSCHALL, C.S.; LOBATO, J.F.P. Comportamento reprodutivo de vacas de corte primíparas submetidas a três lotações em campo nativo. Revista Brasileira de Zootecnia, v.25, n.1, p.46-57, 1996.

HASENACK, H.; CORDEIRO, J.L.P.; DA COSTA, B.S.C. Cobertura vegetal atual do Rio Grande do Sul. In: SIMPÓSIO DE FORRAGEIRAS E PRODUÇÃO ANIMAL, 2., 2007, Porto Alegre. Anais... Porto Alegre: UFRGS, 2007. p.15-22.

HAYDOCK, K.P.; SHAW, N.H. The comparative yield method for estimating dry matter yield of pasture. Australian Journal of Agriculture and Animal Husbandry, v.15, p.66-70, 1975.

KLINGMAN, D.L.; MILES, S.R.; MOTT, G.O. The cage method for determining consumption and yield of pasture herbage. Journal Agronomy, v.35, p.739-746, 1943.

LOBATO, J.F.P.; BARCELLOS, J.O. Efeitos da utilização de pastagem melhorada no pós-parto e do desmame aos 100 ou 180 dias de idade no desempenho reprodutivo de vacas de corte. Revista Brasileira de Zootecnia, v.21, n.3, p.385-395, 1992. LOBATO, J.F.P.; ZANOTTA JUNIOR, R.L.D.; PEREIRA NETO, O.A. Efeitos das dietas pré e pós-parto na eficiência reprodutiva de vacas primíparas de corte. Revista Brasileira de Zootecnia, v.27, n.5, p.857-862, 1998b.

LOBATO, J.F.P. Considerações efetivas sobre seleção, produção e manejo para maior produtividade dos rebanhos de cria. In: LOBATO, J.F.P.; KESSLER, A.M.; BARCELLOS, J.O.J. (Eds.). Produção de bovinos de corte. Porto Alegre: PUCRS, 1999. p.286-302.

LOBATO, J.F.P.; MÜLLER, A.; PEREIRA NETO, O.A. et al. Efeitos da idade à desmama dos bezerros sobre o desempenho reprodutivo de vacas de corte primíparas. Revista Brasileira de Zootecnia, v.29, n.6, p.2013-2018, 2000.

LOBATO, J.F.P. A "vaca ideal" e o seu manejo em sistemas de produção de ciclo curto. In: SIMPÓSIO DA CARNE BOVINA: DA PRODUÇÃO AO MERCADO CONSUMIDOR, 1., 2003, São Borja. Anais... Porto Alegre: Universidade Federal do Rio Grande do Sul, 2003. p.9-43.

LOWMAN, B.G.; SCOTT, N.; SOMERVILLE, S. Condition scoring beef cattle. Edinburgh: East of Scotland College of Agriculture. 1973. 8p.

MONJE, A.; HOFER, C.; GALLI, I. Destet precoz. Efecto sobre los vientres, manejo de los terneros e impacto de la tecnica sobre los sistemas de produccion. In: JORNADA DE DIFUSIÓN TECNICA, 1., 1993, Concepción del Uruguai. Destet precoz en cria vacuna. Concepción del Uruguai: INTA; Centro Regional Entre Rios, 1993. 59p.

MOOJEN, E.L.; MARASCHIN, G.E. Potencial produtivo de uma pastagem nativa do Rio Grande do Sul submetida a níveis de oferta de forragem. Ciência Rural, v.32, n.1, p.60-65, 2002 . 
MOORE, C.P.; ROCHA, C.M.C. Reproductive performance of Gyr cows: the effect of weaning age of calves and postpartum energy intake. Journal of Animal Science, v.57, n.4, p.807-814, 1983.

MORAES, A.A.S.; LOBATO, J.F.P. Efeito de duas épocas de desmama no desempenho reprodutivo de vacas de corte. Revista Brasileira de Zootecnia, v.22, n.6, p.1003-1011, 1993.

MORRISON, D.G.; SPITZER, J.C.; PERKINS, J.L. Influence of prepartum body condition score change on reproduction in multiparous beef cows calving in moderate body condition. Journal of Animal Science, v.77, n.5, p.1048-1054, 1999.

NABINGER, C. Manejo e produtividade das pastagens naturais do subtrópico brasileiro. In:SIMPÓSIO DE FORRAGEIRAS E PRODUÇÃO ANIMAL, 1., 2006, Porto Alegre. Anais... Porto Alegre: Universidade Federal do Rio Grande do Sul, 2006. p.25-76.

OSORO, K.O. Manejo de las reservas corporales y utilización del pasto en los sistemas de producción de carne com vacas madres estabelecidos en zonas húmedas. Producción y Sanidad Animal, v.4, n.3, p.6-88, 1989.

PERRY, R.C.; CORAH, L.R.; COCHRAN, R.C. et al. Influence of dietary energy on follicular development, serum gonadotropins, and first postpartum ovulation in suckled beef cows. Journal of Animal Science, v.69, n.9, p.3762-3773, 1991.

PIO DE ALMEIDA, L.S.; LOBATO, J.F.P.; SCHENKEL, F.S. Data de desmame e desempenho reprodutivo de vacas de corte. Revista Brasileira de Zootecnia, v.31, n.3, p.1223-1229, 2002.

PÖTTER, B.A.A.; LOBATO, J.F.P. Efeitos de carga animal, pastagem melhorada e da idade de desmame no comportamento reprodutivo de vacas primíparas. Revista Brasileira de Zootecnia, v.33, n.1, p.192-202, 2004.

PÖTTER, L.; LOBATO, J.F.P.; SCHENKEL, F.S. Efeitos do manejo pós-parto de vacas primíparas no desempenho de bezerros de corte até um ano de idade. Revista Brasileira de Zootecnia, v.33, n.2, p.423-433, 2004.

QUADROS, S.A.F.; LOBATO, J.F.P. Efeitos da lotação no comportamento reprodutivo de vacas de corte primíparas. Revista Brasileira de Zootecnia, v.25, n.1, p.23-35, 1996.
RESTLE, J.; VAZ, F.N. Desmame precoce de terneiros. In: SIMPÓSIO INTERNACIONAL SOBRE PRODUÇÃO INTENSIVA DE GADO DE CORTE, 2., 1998, São Paulo. Anais... São Paulo, 1998. p.3-9.

RESTLE, J.; POLLI, V.A.; ALVES FILHO, D.C. et al. Desenvolvimento de bovinos de corte de diferentes grupos genéticos desmamados aos 3 ou 7 meses de idade. Revista Brasileira de Zootecnia, v.28, n.5, p.1023-1030, 1999b.

RESTLE, J.; VAZ, RZ.; ALVES FILHO, D.C. et al. Desempenho de vacas Charolês e Nelore desterneiradas aos três ou sete meses. Revista Brasileira de Zootecnia, v.30, n.2, p. 499-507, 2001.

RICE, L.E. Nutrition and the development of replacement heifers. Veterinary Clinics of North America. Food Animal Practice, v.7, n.1, p.27-42, 1991.

RICHARDS, M.W.; WETTEMANN, R.P.; SCHOENEMANN, H.M. Onset of anestrus in nutritionally restricted Hereford cows. Journal of Animal Science, v.63, n.2, p.62-70, 1989.

ROVIRA, J. Reproducción y manejo de los rodeos de cria Montevideo: Hemisferio Sur, 1974. 293p.

ROVIRA, J. Manejo nutritivo de los rodeos de cria em pastoreio. Montevideo: Hemisferio Sur, 1996. 288p.

SIMEONE, A.; LOBATO, J.F.P. Efeitos da lotação em campo nativo e do controle da amamentação no comportamento reprodutivo de vacas de corte primíparas. Revista Brasileira de Zootecnia, v.25, n.6, p.1216-1227, 1996.

SPITZER, J.C.; MORRISON, D.G.; WETTEMANN, R.P. et al. Reproductive responses and calf birth and weaning weights as affected by body condition at parturition and postpartum weight gain in primiparous beef cows. Journal of Animal Science, v.73, n.5, p.1251-1257, 1995.

STATISTICAL ANALYSIS SYSTEM - SAS. User's guide: basic and statistics, Version 8.02. Cary: 2001. v.1, 890p; v.2, 1686p.

WILTBANK, J.N.; ROWDEN, W.W.; INGALLS, J.E. et al. Effect of energy level on reproductive phenomena of mature Hereford cows. Journal of Animal Science, v.21, n.2, p.219-225, 1962. 